\title{
Cardiospecific microRNA Plasma Levels Correlate with Troponin and Cardiac Function in Patients with ST Elevation Myocardial Infarction, Are Selectively Dependent on Renal Elimination, and Can Be Detected in Urine Samples
}

\author{
Olof Gidlöf Patrik Andersson Jesper van der Pals Matthias Götberg \\ David Erlinge \\ Department of Cardiology, Skåne University Hospital, Lund University, Lund, Sweden
}

\section{Key Words}

microRNA - Blood - Myocardial infarction - Biomarker • miR-208b

\begin{abstract}
Objectives: Circulating microRNAs (miRNAs) are promising as biomarkers for various diseases. We examined the release patterns of cardiospecific miRNAs in a closed-chest, large animal ischemia-reperfusion model and in patients with ST elevation myocardial infarction (STEMI). Methods: Six anesthetized pigs were subjected to coronary occlusion-reperfusion. Plasma, urine, and clinical parameters were collected from 25 STEMI patients undergoing primary percutaneous coronary intervention. miRNA was extracted and measured with qPCR. Results: In the pig reperfusion model miR-1, miR$133 a$, and miR-208b increased rapidly in plasma with a peak at 120 min, while miR-499-5p remained elevated longer. In patients with STEMI all 4 miRNAs increased abruptly from 70-fold to 3,000-fold in plasma, with a peak within $12 \mathrm{~h}(\mathrm{p}<$ 0.01). miR-1 and miR-133a both correlated strongly with the glomerular filtration rate (GFR), indicating renal elimination. This was confirmed by detection of miR-1 and miR-133a, but not miR-208b or miR-499-5p, in urine. Peak values of miR208b correlated with peak troponin and the ejection fraction. Conclusion: We demonstrate a distinct and rapid in-
\end{abstract}

crease in levels of cardiospecific miRNA in the circulation after myocardial infarction. Release of miRNAs correlated with cardiomyocyte necrosis markers, the ejection fraction, and the GFR, indicating a possible role for these molecules as biomarkers for the diagnosis of STEMI as well as the prediction of long-term complications.

Copyright $\odot 2011$ S. Karger AG, Basel

\section{Introduction}

Ischemic heart disease is the leading cause of death in developed countries, and each year more than 3 million people are estimated to have an acute ST elevation myocardial infarction (STEMI) [1]. Early diagnosis and swift reperfusion of the occluded coronary vessel is essential for limiting myonecrosis and reducing morbidity and mortality. Cardiac biomarkers, i.e. proteins that leak out into the blood stream from necrotic cardiomyocytes, are of great clinical use for establishing a timely and correct diagnosis. Cardiac troponin $\mathrm{T}$ and I are detectable in the blood within 3-6 h of myocardial damage and are widely accepted as the most reliable biomarkers for the diagnosis of myocardial infarction today [2-4].

MicroRNAs (miRNAs) are short ( $\sim 22$ nucleotide) endogenous RNAs that are essential modulators of gene ex-

\section{KARGER}

Fax +41613061234 E-Mail karger@karger.ch www.karger.com

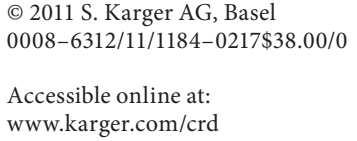

Prof. David Erlinge, $\mathrm{MD}, \mathrm{PhD}$

Department of Cardiology

Lund University Hospital

SE-221 85 Lund (Sweden)

Tel. +46 461725 97, E-Mail david.erlinge@ med.lu.se 
Table 1. Patient characteristics

\begin{tabular}{lc}
\hline Patients & 25 \\
Women & $5(20)$ \\
Hypertension & $9(36)$ \\
Diabetes mellitus & $3(12)$ \\
Hyperlipidemia at admission & 0 \\
Current smoker & $10(40)$ \\
Infarct-related artery & \\
$\quad$ LAD & $14(56)$ \\
Cx & $5(20)$ \\
RCA & $6(24)$ \\
Symptoms-to-reperfusion time (min) & \\
$\quad<100$ & $4(16)$ \\
$\quad 100-180$ & $10(40)$ \\
$\quad 181-360$ & $5(20)$ \\
$361-600$ & $2(8)$ \\
$>600$ & $1(4)$ \\
$\quad$ Unknown & $3(12)$ \\
TIMI 3 flow post-PCI & $24(96)$ \\
Ejection fraction & \\
$>55$ & $11(44)$ \\
$\quad 45-55$ & $2(8)$ \\
$35-45$ & $10(40)$ \\
$25-35$ & $2(8)$ \\
$<25$ & 0 \\
Cardiovascular death within 3 months of AMI & $1(4)$ \\
Rehospitalization for ACS within 3 months & \\
of AMI & 0 \\
GFR (ml/min) & \\
$>90$ & $10(40)$ \\
$\quad 60-90$ & $11(44)$ \\
$\quad<30-59$ & $1(4)$ \\
\hline & \\
& \\
& \\
&
\end{tabular}

All values are presented as numbers (\%). All patients received hyperlipidemia treatment at admission. $\mathrm{Cx}=$ Circumflex; $\mathrm{RCA}=$ right coronary artery; TIMI = thrombolysis in myocardial infarction; $\mathrm{PCI}=$ percutaneous coronary intervention; $\mathrm{AMI}=$ acute myocardial infarction; ACS = acute coronary syndrome.

pression. These noncoding RNA molecules act by pairing with complimentary regions in the $3^{\prime}$-untranslated region of target mRNA, thereby suppressing gene expression [5]. At present, more than 900 human miRNA species have been reported in miRBase [6] release 15 (http:// mirbase.org), and many of them appear to be expressed in a tissue-specific manner [7]. Differential expression of certain miRNA species has been linked with pathological processes such as cancer [8], inflammation [9], and cardiovascular disease [10-12]. miRNA has been shown to be important for cardiac development, and knockout of miR-1 results in cardiomyopathy [13]. The remarkable stability of miRNAs in blood [14] and urine [15] have also made them interesting candidates as biomarkers for various pathological conditions. Certain miRNA species that have been shown to be highly enriched either in cardiac and skeletal muscle in general (miR-1, miR-133a, and miR-499-5p) or specifically in cardiomyocytes (miR-208a and miR-208b) are released into the circulation following myocardial infarction. Several recent studies have aimed to demonstrate the usefulness of some of these miRNAs as cardiac biomarkers with promising results [16-20]. The aim of our study was to investigate the levels of cardiospecific miRNAs in plasma following myocardial infarction and to evaluate their usefulness as markers of cardiac cell death and cardiac function.

\section{Materials and Methods}

Porcine Model of Myocardial Infarction

The procedure has been described in detail previously [21]. Briefly, 6 healthy 40 - to $50-\mathrm{kg}$ domestic pigs were anesthetized and a 3.0-3.5 $\times 20 \mathrm{~mm}$ Maverick Monorail angioplasty balloon (Boston Scientific Scimed, Maple Grove, Minn., USA) was positioned in the proximal left anterior descending artery (LAD). Ischemia was induced by inflation of the angioplasty balloon for $40 \mathrm{~min}$. Total occlusion of the LAD during inflation of the balloon and restoration of blood flow after deflation was verified with angiograms. Blood samples were drawn before occlusion and every $30 \mathrm{~min}$ for a total of $150 \mathrm{~min}$ after inflation of the balloon. All pigs were sacrificed after $4 \mathrm{~h}$.

\section{Patients}

Patients eligible for inclusion were those undergoing primary percutaneous coronary intervention at Skåne University Hospital Lund due to an STEMI. All patients gave their written approval for participating in the study. The study group included 25 patients, $20(80 \%)$ of whom were men. The mean age of the patients was 64.56 years $(S E M=2.70)$. Patient characteristics are summarized in table 1 . Healthy volunteers recruited at the Biomedical Centre in Lund, Sweden, were used as controls. The control group included 7 men (64\%) and 4 women (36\%) with a mean age of 65.09 (SEM = 3.51).

This study was carried out according to the principles of the Declaration of Helsinki and was approved by the local ethics committee of Skåne University Hospital.

\section{Sample Collection and Handling}

The first blood sample was obtained by venipuncture within $24 \mathrm{~h}$ of the onset of symptoms, the second within $48 \mathrm{~h}$, and the third within $72 \mathrm{~h}$. Elevation of cardiospecific miRNAs in the setting of myocardial infarction has previously been shown to increase rapidly, peaking within hours of the presentation of symptoms [16]. The initial samples were therefore divided into 2 groups depending on whether they were collected before or after a cutoff value of $12 \mathrm{~h}(\mathrm{n}=9,<12 \mathrm{~h} ; \mathrm{n}=16,>12 \mathrm{~h})$. Additional blood samples were collected 3-6 months after discharge. The samples were centrifuged at 1,600 $\mathrm{g}$ for $15 \mathrm{~min}$ within $2 \mathrm{~h}$ of collection, followed by aspiration of the plasma, which was stored at $-80^{\circ} \mathrm{C}$. A urine sam- 
ple was collected in a subset of STEMI patients $(n=8)$ within $24 \mathrm{~h}$ of the onset of symptoms and stored at $-80^{\circ} \mathrm{C}$. To test the stability of miRNA in urine during freezing/thawing, urine samples from 3 patients were subjected to 4 cycles of freezing/thawing and aliquots were taken in each cycle for RNA preparation.

RNA Isolation and Real-Time Quantitative RT-PCR

Plasma or urine was mixed with TRIzol LS (Invitrogen, Carlsbad, Calif., USA) in a 1:3 ratio and the samples were homogenized by vortexing $>30 \mathrm{~s}$. RNA was then isolated using an miRNeasy mini kit (Qiagen, Hilden, Germany) according to the manufacturer's instructions. RNA quantity and quality were assessed by NanoDrop (NanoDrop Products, Wilmington, Del., USA) and a Bioanalyzer (Agilent, Santa Clara, Calif., USA) using the 2100 Small RNA assay. cDNA was synthesized from 20 ng of total RNA using an miRCURY LNA Universal cDNA synthesis kit (Exiqon, Vedbaek, Denmark) according to the manufacturer's instructions. Quantitative RT-PCR (qRT-PCR) was carried out in 20- $\mu$ l triplicate reactions with Fast SYBR Green Master Mix (Applied Biosystems, Carlsbad, Calif., USA) and LNA primer sets (Exiqon) specific for miR-1, miR-133a, miR-208a, miR-208b, miR-499$5 \mathrm{p}$, and miR-16 according to the manufacturer's protocol on a StepOnePlus Real-Time PCR System (Applied Biosystems).

\section{Analysis of $q R T-P C R$ Data}

The threshold cycle (Ct) is defined as the fractional PCR cycle number at which the fluorescence reaches a given threshold. For the plasma samples, Ct values for the miRNAs of interest were normalized against the arbitrary value of 40 and expressed relative to the mean of the control samples according to the $2^{-\Delta \Delta \mathrm{Ct}}$ method. The levels of miRNA in urine samples were normalized to an exogenous miRNA spike-in (Exiqon) and expressed as relative quantities $\left(2^{-\Delta \mathrm{Ct}}\right)$. The porcine miRNA data was normalized against baseline values and the maximum value in each pig during the time course. Samples where no amplification could be detected were defined as having a Ct value of 40 . An interplate calibrator sample was used to adjust for run-to-run variation.

\section{Statistical Analysis}

All statistical analyses were carried out using GraphPad Prism 4.0 software (GraphPad Software, Inc., La Jolla, Calif., USA). Differences in miRNA levels were analyzed using 1-way ANOVA with Bonferroni's multiple comparisons post hoc test. Normality tests of all parameters were performed using the D'Agostino-Pearson omnibus method. Correlations between circulating miRNA levels and clinical parameters were performed using Spearman's rank correlation coefficient. $\mathrm{p}<0.05$ was considered statistically significant. All error bars represent the standard error of the mean (SEM).

\section{Results}

\section{Levels of miRNA in a Porcine Myocardial Infarction} Model

We wanted to study the levels of cardiospecific miRNAs following induction of cardiac ischemia in a large animal model and evaluate how rapidly they are re- leased and eliminated. In order to accurately reflect the therapy given to patients in the clinic, we used an occlusion-reperfusion protocol in a closed-chest pig model. We observed a significant increase in miR-1, miR-133a, miR208b, and miR-499-5p after cardiac ischemia (fig. 1). None of the miRNAs could be detected during the 40 min occlusion period, but all of them started to increase 20 min after reperfusion (60-min time point in fig. 1). The dynamics of miR-1, miR-133, and miR-208b were especially rapid, peaking after $120 \mathrm{~min}$, followed by a fast 25 $50 \%$ reduction already $30 \mathrm{~min}$ later. The level of miR-499$5 \mathrm{p}$, however, remained high even at $150 \mathrm{~min}$, indicating slower elimination rates. miR-208a could not be detected.

Levels of Circulating miR-1, miR-133a, miR-208b, and miR-499-5p Are Elevated in Patients with STEMI

The levels of circulating miR-1, miR-133a, miR-208b, and miR-499-5p were elevated within $12 \mathrm{~h}$ of the onset of symptoms in STEMI patients (fig. 2). miR-1 was increased 300 -fold ( $\mathrm{p}<0.01$ ), miR-133a 70-fold ( $\mathrm{p}<0.01$ ), miR-208b 3,000-fold ( $\mathrm{p}<0.001$ ), and miR-499-5p 250-fold ( $<<$ 0.01 ) as compared to healthy controls. The levels of miR$208 \mathrm{~b}$ and $\mathrm{miR}-499-5 \mathrm{p}$ remained 320 - and 50-fold elevated after 2 days ( $\mathrm{p}=0.10$ and $\mathrm{p}=0.32$, respectively) and miR-208b was still 70-fold higher than at baseline after 3 days $(\mathrm{p}=0.20)$. The level of miR-16, which is not tissue specific, did not change significantly during the time course (data not shown). miR-208a could not be detected. Peak levels for all pairs of miRNAs except miR-1 versus miR-208b or 499-5p correlated at day 1 . At day 3, miR-1 and miR-133a correlated very strongly with each other $(\mathrm{p}<0.0001)$, as did miR-208b with miR-499-5p ( $\mathrm{p}=$ 0.0033). All correlation data are summarized in table 2 .

\section{miR-1 and miR-133 Are Detectable in Urine after Myocardial Infarction}

The rapid clearance of circulating miRNA after $12 \mathrm{~h}$ following myocardial infarction led us to speculate whether these miRNAs are excreted in urine. We were able to detect miR-1 and miR-133a, but not miR-499-5p or miR-208b, in the urine of STEMI patients $(\mathrm{n}=8)$ within $24 \mathrm{~h}$ of the onset of symptoms (fig. 3). These results suggest that the route of degradation and/or excretion of miR-499-5p and miR-208b differs from that of miR-1 and miR-133a.

To ensure that the miRNA stability in urine was not negatively affected by freezing and thawing, we extracted miRNA from urine samples subjected to 4 consecutive freeze-thaw cycles and analyzed the abundance of miR-1 and miR-16 by qRT-PCR. The levels of these miRNA spe- 


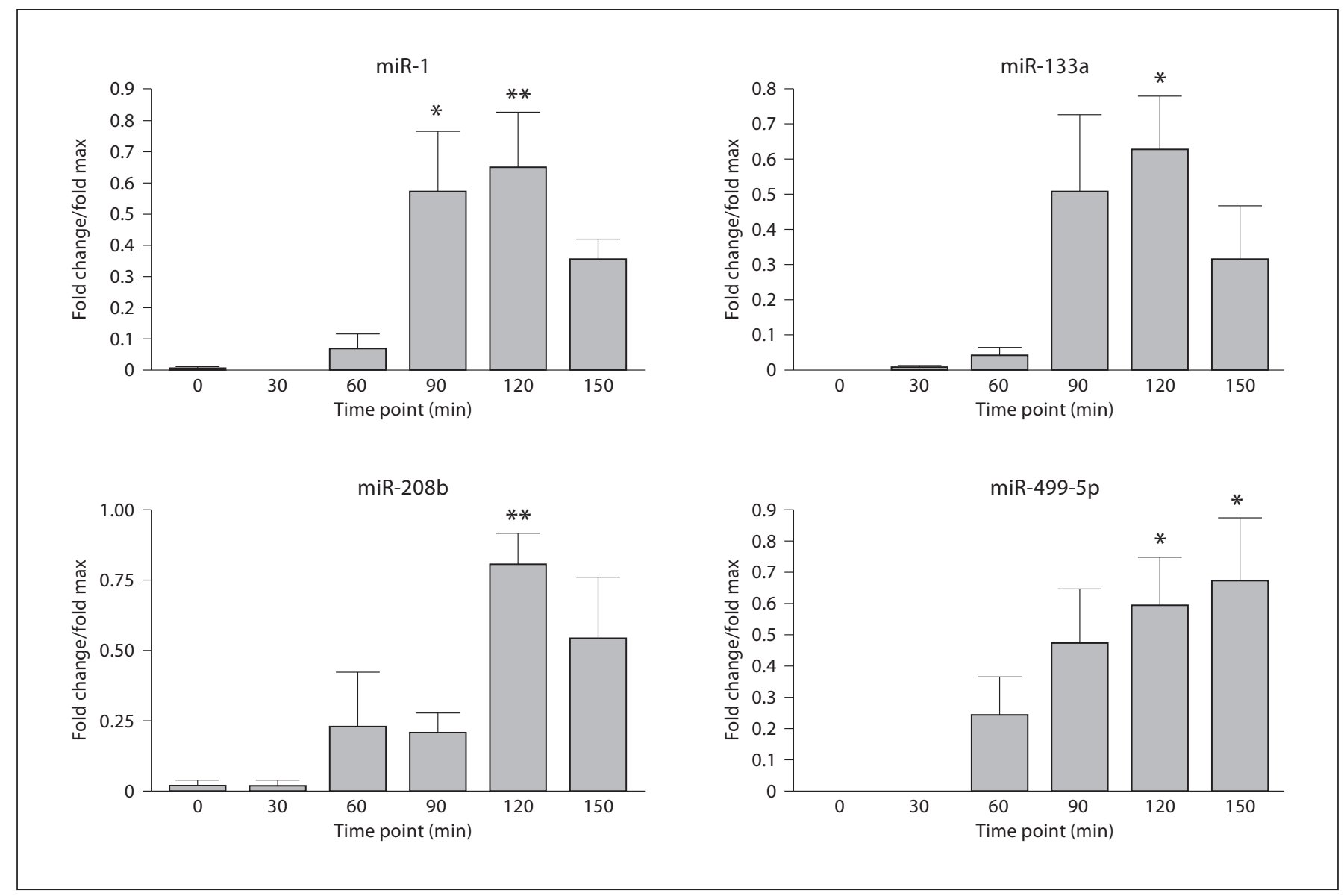

Fig. 1. miRNA release in a closed-chest pig myocardial infarction model $(n=6)$. All data are normalized to baseline values and to the maximum value that each miRNA reached in each pig. ${ }^{*} \mathrm{p}<$ $0.05,{ }^{* *} \mathrm{p}<0.01$. Number of nondetected samples: miR-1, 1 at
$0 \mathrm{~min}$ and 3 at $30 \mathrm{~min}$; miR-133a, 1 at $0 \mathrm{~min}$ and 1 at $30 \mathrm{~min}$; miR208b, 5 at $0 \mathrm{~min}, 5$ at $30 \mathrm{~min}, 1$ at $90 \mathrm{~min}$, and 1 at $150 \mathrm{~min}$, and miR-499-5p, 1 at $0 \mathrm{~min}$ and 3 at $30 \mathrm{~min}$. $\max =$ Maximum. cies were not significantly affected by the treatment. The mean Ct for miR-1 changed from $34.42(\mathrm{SEM}=0.90)$ at cycle 1 to $34.79(\mathrm{SEM}=0.89)$ at cycle 4 and from 25.72 $(\mathrm{SEM}=0.16)$ to $25.93(\mathrm{SEM}=0.34)$ for $\mathrm{miR}-16(\mathrm{n}=3)$.

\section{Clinical Correlations}

To evaluate the significance of increased levels of circulating cardio-miRs following myocardial infarction, we analyzed whether the levels of these miRNAs correlated with a set of clinical parameters. We found that the peak level of circulating troponin $\mathrm{T}$ correlated significantly with the peak values of miR-208b $\left(p=0.01, r^{2}=\right.$ 0.25 ) at day 1 (fig. 4a). Furthermore, we found negative correlations between the ejection fraction and the peak miR-208b $\left(p=0.01, r^{2}=0.32\right)$ at day 1 (fig. $\left.4 b\right)$. However, neither of the other miRNAs correlated with troponin or the ejection fraction. The peak troponin T correlated significantly with the ejection fraction $\left(\mathrm{p}=0.01, \mathrm{r}^{2}=0.33\right)$.

Finally, we found significant negative correlations between the glomerular filtration rate (GFR) and day 3 levels of miR-1 $\left(\mathrm{p}=0.01, \mathrm{r}^{2}=0.27\right)$ and miR-133a $(\mathrm{p}=0.04$, $\mathrm{r}^{2}=0.17$; fig. 5) but no correlation with miR-208b ( $\mathrm{p}=$ $\left.0.09, \mathrm{r}^{2}=0.12\right)$ or miR-499-5p $\left(\mathrm{p}=0.14, \mathrm{r}^{2}=0.097\right)$. Neither the peak troponin $\mathrm{T}$ nor the ejection fraction correlated significantly with the GFR.

\section{Receiver Operating Characteristic Analysis}

To evaluate the usefulness of circulating miRNA as biomarkers for STEMI, we performed a receiver operating characteristic (ROC) analysis (fig. 6). Data from STEMI patients from whom samples were taken within $12 \mathrm{~h}(\mathrm{n}=9)$ and healthy controls $(\mathrm{n}=11)$ were included 


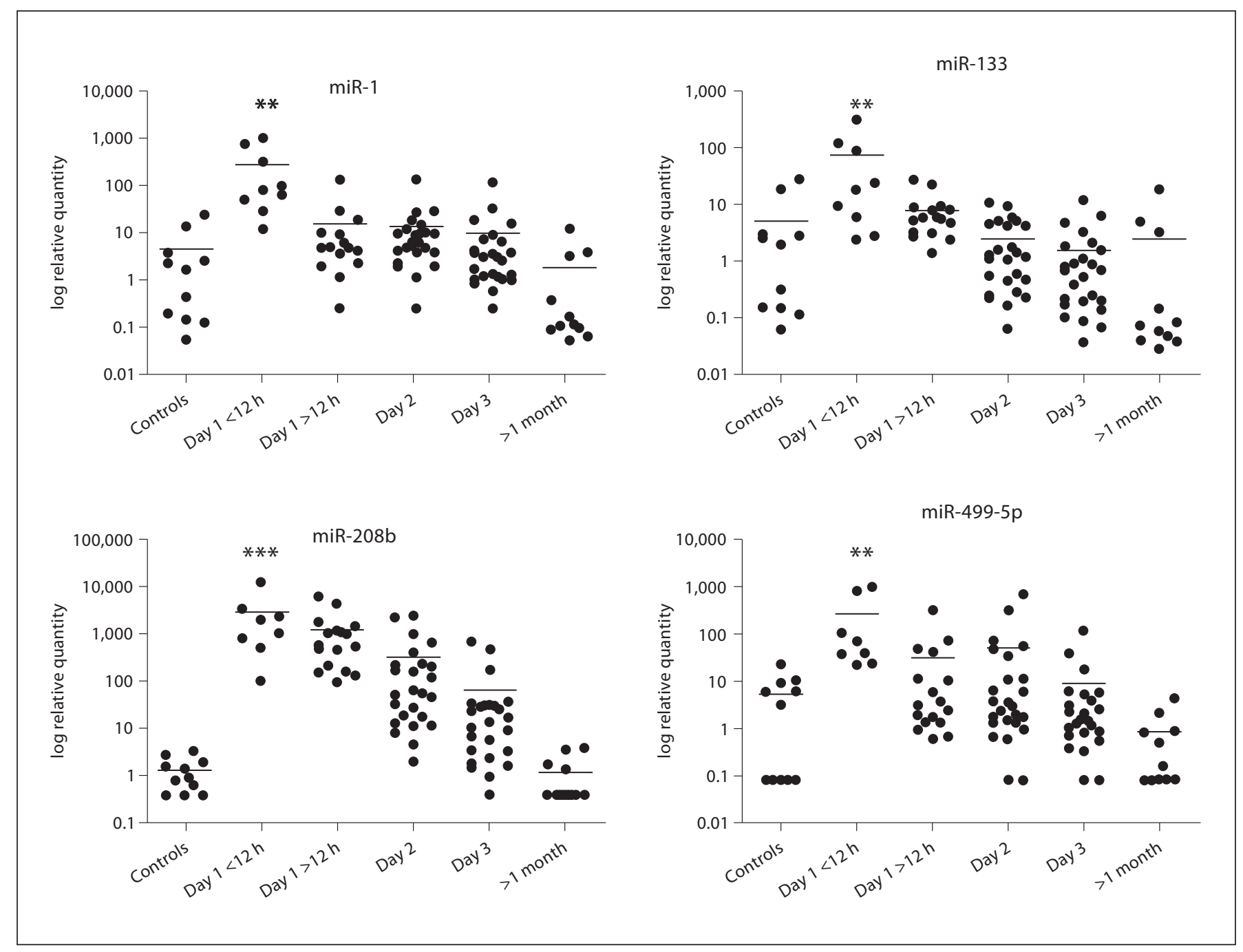

Fig. 2. Dynamic changes of circulating miRNA from $<12 \mathrm{~h}$ to $>1$ month in patients with STEMI $(\mathrm{n}=25)$. All data are normalized against the mean of the control samples $(n=11) .{ }^{* *} \mathrm{p}<0.01$,
*** $\mathrm{p}<0.001$. Number of nondetected samples: miR-499-5p, 5 in the control group, 2 at day 2,1 at day 3 , and 7 at $>1$ month; miR208 b, 3 in the control group, 1 at day 3 , and 8 at $>1$ month.

Table 2. Intercorrelations of circulating miRNAs at days 1 and 3 following STEMI

\begin{tabular}{|c|c|c|c|c|}
\hline & \multicolumn{2}{|l|}{ Day 1} & \multicolumn{2}{|l|}{ Day 3} \\
\hline & $\mathrm{p}$ & $\mathrm{r}$ & $\mathrm{p}$ & $\mathrm{r}^{2}$ \\
\hline miR-1 versus miR-133a & 0.0008 & 0.6358 & $<0.0001$ & 0.7738 \\
\hline miR-1 versus miR-208b & 0.0732 & 0.3723 & 0.1206 & 0.3186 \\
\hline miR-1 versus miR-499-5p & 0.1569 & 0.2983 & 0.9774 & -0.005965 \\
\hline miR-133a versus miR-208b & 0.0001 & 0.6945 & 0.0101 & 0.5046 \\
\hline miR-133a versus miR-499-5p & 0.002 & 0.5878 & 0.1533 & 0.2943 \\
\hline miR-208b versus miR-499-5p & 0.0084 & 0.5155 & $<0.0033$ & 0.5643 \\
\hline
\end{tabular}

Statistically significant correlations are depicted in bold. 
Fig. 3. Detection of cardiospecific miRNAs in urine after STEMI. Data are expressed relative to the amount of exogenous miRNA spike-in $(\mathrm{n}=8)$. Number of nondetected samples: 1 for miR-1 and 3 for miR-133a. ND = Not detectable.
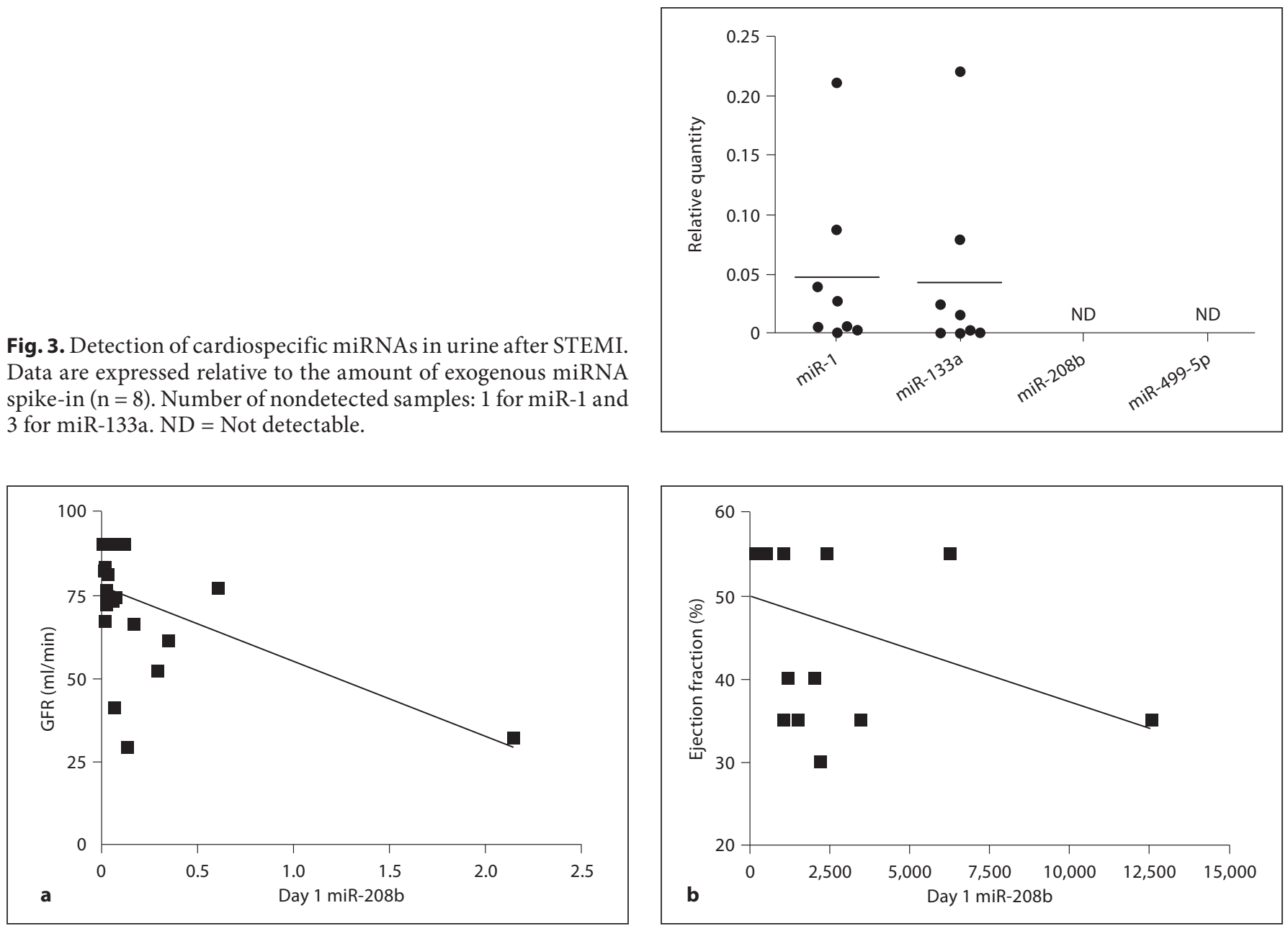

Fig. 4. Correlation of levels of miR-208b at day 1 with troponin $T\left(p=0.01, r^{2}=0.25\right)(a)$ and the ejection fraction $\left(\mathrm{p}=0.01, \mathrm{r}^{2}=0.32\right)(\mathbf{b})$ in STEMI patients $(\mathrm{n}=25)$.
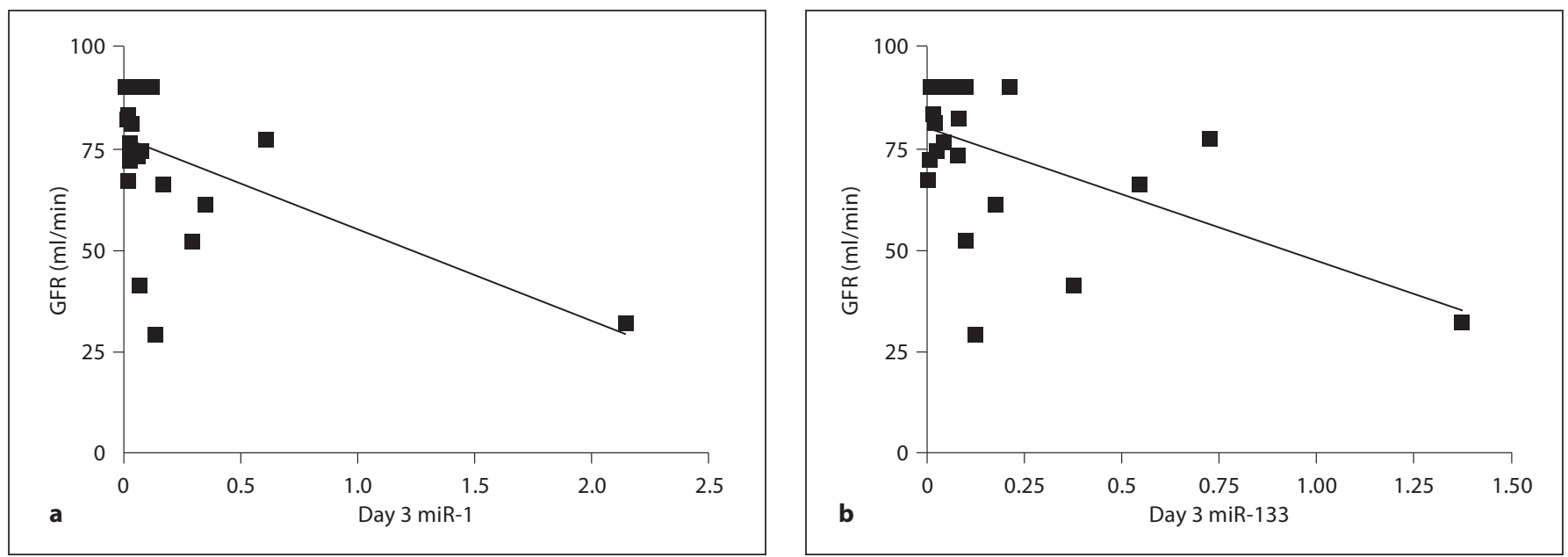

Fig. 5. Correlation of the GFR with miR-1 $\left(\mathrm{p}=0.01, \mathrm{r}^{2}=0.27\right)(\mathbf{a})$ and $\mathrm{miR}-133\left(\mathrm{p}=0.04, \mathrm{r}^{2}=0.17\right)$ (b) at day 3 in STEMI patients $(n=25)$. 


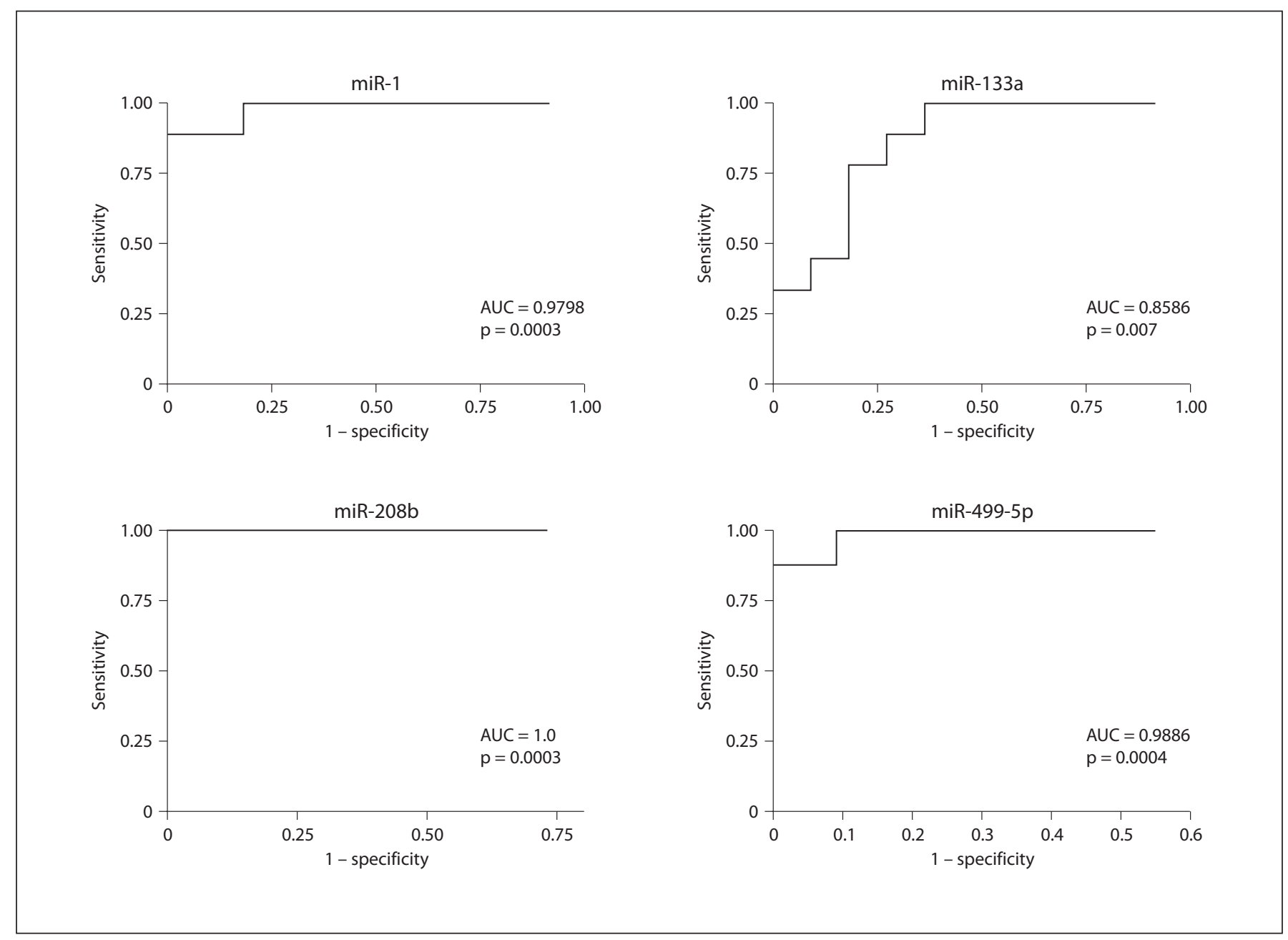

Fig. 6. ROC curves for circulating miRNA within 12 h of STEMI. Patients, $\mathrm{n}=9$; controls, $\mathrm{n}=11$.

in the analysis. The ROC curves strongly distinguished between the 2 groups. miR-208b stood out as the best candidate, with $100 \%$ specificity and sensitivity. The other miRNAs had an area under the curve of 0.98 (95\% CI 0.93-1.03) for miR-1, 0.86 (95\% CI 0.69-1.02) for miR133a, and 0.99 (95\% CI 0.93-1.03) for miR-499-5p.

\section{Discussion}

The observation that miRNAs are stable and present in the circulation has led to a rapidly growing number of reports on the use of these molecules as biomarkers for various diseases. In the case of coronary artery disease miR-1, miR-133a, miR-208a, miR-208b, and miR-499-5p are considered cardio- or skeletal muscle specific and are all candidates as biomarkers for myocardial infarction. This led us to investigate the dynamics of these miRNAs in the immediate response to myocardial infarction in a closed-chest ischemia-reperfusion pig model as well as in patients with STEMI. To our knowledge, no previous studies have been conducted on circulating miRNA following myocardial infarction in a large animal model. The studies performed so far on circulating miRNA following cardiac ischemia in animal models $[16,18]$ induced myocardial infarction by permanent ligation of a coronary artery. In contrast, we chose to induce myocardial infarction in an occlusion-reperfusion manner that we believe better reflects the treatment given to patients in the clinic. In addition, we observed faster kinetics with regard to miR-1 and miR-133a than previously reported, probably secondary to reperfusion. The results 
showed that miR-1, miR-133a, and miR-208a increased rapidly and peaked within $120 \mathrm{~min}$, whereas miR-499$5 \mathrm{p}$ continued to increase even after $150 \mathrm{~min}$ following the onset of cardiac ischemia. In patients with STEMI there was a massive increase in the levels of cardiospecific miRNAs in the circulation compared to healthy controls, followed by a return to near baseline of miR-1 and miR-133a after $12 \mathrm{~h}$ of the onset of symptoms. The levels of miR-208b and miR-499-5p decreased more slowly and were still elevated 300 - and 50 -fold, respectively, 2 days after the STEMI. These findings are concurrent with the work of D'Alessandra et al. [18] who suggest that miR-499-5p has a slower dynamic than miR-1 and miR-133a.

In a very recent study, miR-208b was shown to be elevated in plasma following myocardial infarction [22]. Of the miRNAs included in this study, miR-208b showed the most marked increase (3,000-fold) and was still elevated 70 -fold after 3 days.

miR-208a has recently been proposed as an ideal biomarker for the diagnosis of myocardial infarction [16, 17]. The expression of miR-208a is highly restricted to cardiomyocytes [16], and it has been shown to be present in the circulation of patients with acute myocardial infarction. However, in concordance with a recent report [18], we could not readily detect miR-208a in the blood of these patients or in the porcine ischemia-reperfusion model. This might be explained by an extremely rapid half-life of circulating miR-208a. The earliest patient samples in this study were taken within $12 \mathrm{~h}$ of the onset of symptoms, in contrast to the work of Wang et al. [16] where the first sample was taken within $4 \mathrm{~h}$. Thus, it is feasible that the levels of circulating miR-208a might have sunken below the detection limit of our assay even in the earliest samples. Nevertheless, a molecule with such a short half-life might not be optimally suited as a biomarker.

Cardiac troponins are considered the gold standard of biomarkers for the diagnosis of myocardial infarction at present. We found that peak levels of miR-208b correlated with peak levels of troponin T, suggesting that they can be used as markers of acute cardiomyocyte cell death. ROC analysis showed that miR-208b had $100 \%$ sensitivity and specificity in distinguishing between STEMI patients where samples were taken within $12 \mathrm{~h}$ and healthy controls, albeit in a rather limited study sample. This suggests that of the miRNAs included in this study miR-208b is the most reliable biomarker for STEMI.

We show for the first time a correlation between the circulating miRNA levels and ejection fraction of pa- tients after myocardial infarction. The peak amount of miR-208b in the blood correlated negatively with the ejection fraction. Thus, it is possible that quantifying cardiospecific miRs in the circulation might not only be of use in diagnosing cardiac ischemia but could potentially also be helpful in prognosticating long-term cardiac function and the risk of developing heart failure. However, the significance of this finding needs to be confirmed in a larger patient sample, and the possible biological link between miRNA and the ejection fraction remains to be elucidated. Troponin $\mathrm{T}$ also correlated significantly with the ejection fraction, as previously described [23]. miR-1, miR-133a, and miR-499-5p did not correlate with $\mathrm{TnT}$ or EF, indicating that they do not reflect cardiac damage as well as miR-208b does.

miR-208b and miR-499-5p remained markedly elevated in patients even 2 or 3 days after STEMI. The time profile indicates a reduced elimination rate compared to miR-1 and miR-133a. Interestingly, we found negative correlations between the GFR and the amount of miR-1 and miR-133a, but not miR-208b or miR-499-5p, in the blood 3 days after STEMI, indicating possible renal elimination of the former 2 . This was confirmed by detection of miR-1 and miR-133a (but not miR-208a or miR-499$5 p)$ in the urine of patients within 1 day of their STEMI. Intrarenal expression of miR-200a and miR-205 correlates with the GFR in patients with hypertensive nephrosclerosis [24], but no association has previously been found between circulating miRNA and kidney function. Renal failure increases mortality substantially after myocardial infarction [25], and the link between kidney function and circulating miRNAs merits more extensive study.

Elucidating the possible biological role of cardiospecific miRNAs in the circulation after STEMI is beyond the scope of this paper. However, considering the recent reports describing cell-to-cell transport of miRNAs [26] and of miRNAs as paracrine signaling molecules [27] one might speculate that the presence of miRNAs in circulation is not merely a by-product of myocardial necrosis but also implies a functional role for these molecules. miR-1 and miR-133a have been shown to regulate cardiomyocyte apoptosis through different mechanisms [28, 29], whereas miR-208b and miR-499 have been shown to affect muscle function and performance by regulating myosin gene expression [30]. This might point towards a cardioprotective role for these miRNAs in the setting of myocardial infarction. These questions need to be addressed thoroughly in future studies. 
Our results demonstrate that there are clear differences in the properties of cardiospecific miRNA. The release pattern and correlation with cardiomyocyte necrosis markers and the ejection fraction was restricted to miR208b. miR-208b also exhibited by far the highest increase in humans $(>3,000$-fold) and correlated with troponin. It may be the most sensitive miR for detection of cardiac ischemia, as suggested by the results of the ROC analysis. Furthermore, the elimination pattern differed in that miR-1 and miR-133a seem to be dependent on renal elimination and are detectable in urine, while miR-208b and miR-499-5p are not. This could be important for understanding miRNAs and their roles in cardiovascular disease in the future.

We could detect cardiospecific miRNAs in the circulation as early as $90 \mathrm{~min}$ after occlusion of the LAD in the pig model of myocardial infarction. Assuming that the time frame is comparable in humans this could mean a reduction in the time to determine the diagnosis and could possibly reduce the morbidity and mortality of myocardial infarction. Moreover, the finding that circulating cardiospecific miRNAs correlate with the ejection fraction and GFR might possibly imply a broader role for these molecules as biomarkers for MI as tools not only for diagnosis but also for estimating the risk of long-term complications. Nevertheless, the data presented here are based on a rather limited study population and the results need to be confirmed in a larger sample.

\section{Acknowledgements}

This work was supported by the Swedish Heart and Lung Foundation, the Swedish Scientific Research Council, ALF, and Lund University Hospital funds.

\section{References}

1 White HD, Chew DP: Acute myocardial infarction. Lancet 2008;372:570-584.

-2 Kavsak PA, MacRae AR, Yerna MJ, Jaffe AS: Analytic and clinical utility of a next-generation, highly sensitive cardiac troponin I assay for early detection of myocardial injury. Clin Chem 2009;55:573-577.

-3 Keller T, Zeller T, Peetz D, Tzikas S, Roth A, Czyz E, Bickel C, Baldus S, Warnholtz A, Frohlich M, Sinning CR, Eleftheriadis MS, Wild PS, Schnabel RB, Lubos E, Jachmann N, Genth-Zotz S, Post F, Nicaud V, Tiret L, Lackner KJ, Munzel TF, Blankenberg S: Sensitive troponin I assay in early diagnosis of acute myocardial infarction. $\mathrm{N}$ Engl J Med 2009;361:868-877.

4 Reichlin T, Hochholzer W, Bassetti S, Steuer S, Stelzig C, Hartwiger S, Biedert S, Schaub N, Buerge C, Potocki M, Noveanu M, Breidthardt T, Twerenbold R, Winkler K, Bingisser R, Mueller C: Early diagnosis of myocardial infarction with sensitive cardiac troponin assays. N Engl J Med 2009;361: 858-867.

5 Bartel DP: MicroRNAs: target recognition and regulatory functions. Cell 2009;136: 215-233.

6 Griffiths-Jones S, Saini HK, van Dongen S, Enright AJ: MiRBase: tools for microRNA genomics. Nucleic Acids Res 2008;36:D154D158.

7 Landgraf P, Rusu M, Sheridan R, Sewer A, Iovino N, Aravin A, Pfeffer S, Rice A, Kamphorst AO, Landthaler M, Lin C, Socci ND, Hermida L, Fulci V, Chiaretti S, Foa R, Schliwka J, Fuchs U, Novosel A, Muller RU, Schermer B, Bissels U, Inman J, Phan Q, Chien M, Weir DB, Choksi R, De Vita G,
Frezzetti D, Trompeter HI, Hornung V, Teng G, Hartmann G, Palkovits M, Di Lauro R, Wernet P, Macino G, Rogler CE, Nagle JW, Ju J, Papavasiliou FN, Benzing T, Lichter P, Tam W, Brownstein MJ, Bosio A, Borkhardt A, Russo JJ, Sander C, Zavolan M, Tuschl T: A mammalian microRNA expression atlas based on small RNA library sequencing. Cell 2007;129:1401-1414.

-8 Lu J, Getz G, Miska EA, Alvarez-Saavedra E, Lamb J, Peck D, Sweet-Cordero A, Ebert BL, Mak RH, Ferrando AA, Downing JR, Jacks T, Horvitz HR, Golub TR: MicroRNA expression profiles classify human cancers. Nature 2005;435:834-838.

-9 O'Connell RM, Taganov KD, Boldin MP, Cheng G, Baltimore D: MicroRNA-155 is induced during the macrophage inflammatory response. Proc Natl Acad Sci USA 2007;104: 1604-1609.

10 Zhang C: MicroRNAs: role in cardiovascular biology and disease. Clin Sci (Lond) 2008; 114:699-706.

-11 Bostjancic E, Zidar N, Stajer D, Glavac D: MicroRNAs miR-1, miR-133a, miR-133b and miR-208 are dysregulated in human myocardial infarction. Cardiology 2010;115:163169.

12 Condorelli G, Latronico MV, Dorn GW 2nd: MicroRNAs in heart disease: putative novel therapeutic targets? Eur Heart J 2010;31: 649-658.

13 Rao PK, Toyama Y, Chiang HR, Gupta S, Bauer M, Medvid R, Reinhardt F, Liao R, Krieger M, Jaenisch R, Lodish HF, Blelloch $\mathrm{R}$ : Loss of cardiac microRNA-mediated regulation leads to dilated cardiomyopathy and heart failure. Circ Res 2009;105:585-594.
14 Mitchell P, Parkin R, Kroh E, Fritz B, Wyman S, Pogosova-Agadjanyan E, Peterson A, Noteboom J, O'Briant K, Allen A, Lin D, Urban N, Drescher C, Knudsen B, Stirewalt D, Gentleman R, Vessella R, Nelson P, Martin $\mathrm{D}$, Tewari M: Circulating microRNAs as stable blood-based markers for cancer detection. Proc Natl Acad Sci USA 2008; 105: 10513-10518.

15 Hanke M, Hoefig K, Merz H, Feller AC, Kausch I, Jocham D, Warnecke JM, Sczakiel G: A robust methodology to study urine microRNA as tumor marker: microRNA-126 and microRNA-182 are related to urinary bladder cancer. Urol Oncol 2010;28:655-661.

16 Wang GK, Zhu JQ, Zhang JT, Li Q, Li Y, He J, Qin YW, Jing Q: Circulating microRNA: a novel potential biomarker for early diagnosis of acute myocardial infarction in humans. Eur Heart J 2010;31:659-666.

17 Ji X, Takahashi R, Hiura Y, Hirokawa G, Fukushima Y, Iwai N: Plasma miR-208 as a biomarker of myocardial injury. Clin Chem 2009;55:1944-1949.

18 D'Alessandra Y, Devanna P, Limana F, Straino S, Di Carlo A, Brambilla PG, Rubino M, Carena MC, Spazzafumo L, De Simone M, Micheli B, Biglioli P, Achilli F, Martelli F, Maggiolini S, Marenzi G, Pompilio G, Capogrossi MC: Circulating microRNAs are new and sensitive biomarkers of myocardial infarction. Eur Heart J 2010;31:2765-2773.

19 Ai J, Zhang R, Li Y, Pu J, Lu Y, Jiao J, Li K, Yu B, Li Z, Wang R, Wang L, Li Q, Wang N, Shan $\mathrm{H}$, Yang B: Circulating microRNA-1 as a potential novel biomarker for acute myocardial infarction. Biochem Biophys Res Commun 2010;391:73-77. 
-20 Adachi T, Nakanishi M, Otsuka Y, Nishimura K, Hirokawa G, Goto Y, Nonogi H, Iwai N: Plasma microRNA 499 as a biomarker of acute myocardial infarction. Clin Chem 2010;56:1183-1185.

-21 Gotberg M, van der Pals J, Olivecrona GK, Koul S, Erlinge D: Mild hypothermia reduces acute mortality and improves hemodynamic outcome in a cardiogenic shock pig model. Resuscitation 2010;81:1190-1196.

-22 Corsten MF, Dennert R, Jochems S, Kuznetsova T, Devaux Y, Hofstra L, Wagner DR, Staessen JA, Heymans S, Schroen B: Circulating microRNA-208b and microRNA-499 reflect myocardial damage in cardiovascular disease. Circ Cardiovasc Genet 2010;3:499-506.

-23 Bohmer E, Hoffmann P, Abdelnoor M, Seljeflot I, Halvorsen S: Troponin T concentration 3 days after acute ST-elevation myocardial infarction predicts infarct size and cardiac function at 3 months. Cardiology 2009; 113:207-212.
24 Wang G, Kwan BC, Lai FM, Choi PC, Chow KM, Li PK, Szeto CC: Intrarenal expression of miRNAs in patients with hypertensive nephrosclerosis. Am J Hypertens 2010;23: 78-84.

25 Szummer K, Lundman P, Jacobson SH, Schon S, Lindback J, Stenestrand U, Wallentin L, Jernberg T: Relation between renal function, presentation, use of therapies and in-hospital complications in acute coronary syndrome: data from the SWEDEHEART register. J Intern Med 2010;268:40-49.

26 Valadi H, Ekstrom K, Bossios A, Sjostrand M, Lee JJ, Lotvall JO: Exosome-mediated transfer of mRNAs and microRNAs is a novel mechanism of genetic exchange between cells. Nat Cell Biol 2007;9:654-659.

27 Zernecke A, Bidzhekov K, Noels H, Shagdarsuren E, Gan L, Denecke B, Hristov M, Koppel T, Jahantigh MN, Lutgens E, Wang S, Olson EN, Schober A, Weber C: Delivery of microRNA-126 by apoptotic bodies induces CXCL12-dependent vascular protection. Sci Signal 2009;2:ra81.
28 Tang Y, Zheng J, Sun Y, Wu Z, Liu Z, Huang G: MicroRNA-1 regulates cardiomyocyte apoptosis by targeting $\mathrm{Bcl}-2$. Int Heart J 2009;50:377-387.

-29 Xu C, Lu Y, Pan Z, Chu W, Luo X, Lin H, Xiao J, Shan H, Wang Z, Yang B: The muscle-specific microRNAs miR-1 and miR-133 produce opposing effects on apoptosis by targeting HSP60, HSP70 and caspase-9 in cardiomyocytes. J Cell Sci 2007;120:3045-3052.

30 van Rooij E, Quiat D, Johnson BA, Sutherland LB, Qi X, Richardson JA, Kelm RJ Jr, Olson EN: A family of microRNAs encoded by myosin genes governs myosin expression and muscle performance. Dev Cell 2009;17: 662-673. 